\title{
Post-traumatic anxiety associates with failure of the innate immune receptor TLR9 to evade the pro-inflammatory NFкB pathway
}

\author{
G Zimmerman ${ }^{1}$, G Shaltiel ${ }^{1}$, S Barbash ${ }^{1}$, J Cohen ${ }^{2}$, CJ Gasho ${ }^{3}$, S Shenhar-Tsarfaty ${ }^{1,4}$, H Shalev $^{5}$, SA Berliner ${ }^{4}$, I Shelef ${ }^{3}$, S Shoham ${ }^{6}$, \\ A Friedman ${ }^{2}, \mathrm{H}$ Cohen $^{7}$ and $\mathrm{H}$ Soreq ${ }^{1}$
}

Post-traumatic anxiety notably involves inflammation, but its causes and functional significance are yet unclear. Here, we report that failure of the innate immune system Toll-like receptor 9 (TLR9) to limit inflammation is causally involved with anxietyassociated inflammation and that peripheral administration of specific oligonucleotide activators of TLR9 may prevent posttraumatic consequences in stressed mice. Suggesting involvement of NFKB-mediated enhancement of inflammatory reactions in the post-traumatic phenotype, we found association of serum interleukin-1 $\beta$ increases with symptoms severity and volumetric brain changes in post-traumatic stress disorder patients. In predator scent-stressed mice, the moderate NFkB-activating oligonucleotides mEN101 and its human ortholog BL-7040, but not the canonic NFKB activator oligonucleotide ODN1826, induced anxiolytic effects. In stressed mice, peripherally administered mEN101 prevented delayed stress-inducible serum interleukin-1及 increases while limiting stress-characteristic hippocampal transcript modifications and the anxiety-induced EGR1-mediated neuronal activation. Attesting to the TLR9 specificity of this response, BL-7040 suppressed NFKB-mediated luciferase in transfected cells co-expressing TLR9, but not other TLRs. Furthermore, TLR9-/- mice were mEN101 and BL-7040 resistant and presented unprovoked anxiety-like behavior and anxiety-characteristic hippocampal transcripts. Our findings demonstrate functional relevance of TLR9 in protecting stressed mammals from overreacting to traumatic experiences and suggest using oligonucleotide-mediated peripheral TLR9 activation to potentiate the innate immune system and prevent posttraumatic inflammation and anxiety.

Translational Psychiatry (2012) 2, e78; doi:10.1038/tp.2012.4; published online 21 February 2012

\section{Introduction}

Post-traumatic stress disorder (PTSD) is a severe and longlasting anxiety disorder with recently increasing abundance and social and economic significance. ${ }^{1}$ Apart from their central nervous system impairments, PTSD patients suffer multiple peripheral pathologies, ${ }^{2}$ including persistent inflammation. However, neither the mechanistic origin $(s)^{3}$ nor the functional relevance of PTSD-associated inflammation have been fully understood. ${ }^{4}$ In search for answers, we considered that reactions to trauma span somatic features associated with the ecological context in which they evolved. Thus, hormones released during stress prepare the immune system to cope with physical injuries. ${ }^{5}$ Therefore, anxiety patients and rodents exposed to acute stressors both show elevated serum levels of pro-inflammatory cytokines (for example, interleukin (IL) $-1 \beta$ and IL-6). ${ }^{6,7}$ However, apart from their protective immune functions, such peripheral cytokines access the brain and stimulate specific receptors. ${ }^{8-10}$
Peripheral administration of IL1 $\beta$, for example, potentiates the consolidation of traumatic memories and the exaggerated anxiety responses to subsequent mild stressors, ${ }^{11,12}$ both characteristic symptoms of PTSD. ${ }^{13}$ Likewise, peripheral administration of IL-6 elevates serum acetylcholinesterase (AChE) levels, ${ }^{14}$ limiting the cholinergic surveillance, which prevents excessive inflammation under non-stressed conditions. ${ }^{15}$ Furthermore, the induction and penetration into the brain of pro-inflammatory cytokines during stress reactions may by itself induce anxiogenic effects, ${ }^{9}$ creating a selfpropagating loop between psychological stress and immune activation. Nevertheless, the vast majority of post-traumatized individuals do not develop PTSD; therefore, we predicted that natural mechanism(s) should have evolved to tightly regulate such peripheral reactions and restrain detrimental cognitive and immune consequences, and that the emergence of PTSD may be causally involved with inherited and/or acquired impairments of such surveillance and regulatory mechanisms.

\footnotetext{
${ }^{1}$ The Edmond and Lily Safra Center for Brain Sciences, The Institute of Life Sciences, The Hebrew University of Jerusalem, Jerusalem, Israel; ${ }^{2}$ Department of Physiology and Zlotowski Center of Neuroscience, Ben-Gurion University of the Negev, Beer Sheva, Israel; ${ }^{3}$ Departments of Radiology, Ben-Gurion University of the Negev, Beer Sheva, Israel; ${ }^{4}$ Tel Aviv Sourasky Medical Center and Sackler Faculty of Medicine, Tel-Aviv University, Tel Aviv, Israel; ${ }^{5}$ Department of Psychiatry, Soroka Medical Center, Beer Sheva, Israel; ${ }^{6}$ Research Department, Herzog Hospital, Jerusalem, Israel and ${ }^{7}$ Anxiety and Stress Research Unit, Ben-Gurion University of the Negev, Negev, Israel

Correspondence: Professor H Soreq, The Edmond and Lily Safra Center for Brain Sciences, The Institute of Life Sciences, The Hebrew University of Jerusalem, Jerusalem 91904, Israel.

E-mail: soreq@cc.huji.ac.il
}

Keywords: inflammation; innate immune system; NFKB; oligonucleotide; post-traumatic stress; TLR9

Received 11 October 2011; revised 12 December 2011; accepted 8 January 2012 
The master regulator of inflammation is the transcriptional activator $\mathrm{NF}_{\kappa \mathrm{B}}$, the functioning of which can be manipulated by CpG-including oligonucleotides (ODNs) through the biosensor activities of Toll-like-receptors (TLRs). ${ }^{16,17}$ TLRs are pattern recognition receptors expressed on the cell surface and/or in endosomal membranes of cells of the innate immune system. By recognizing specific DNA motifs, especially those including CpG dinucleotides, TLRs can detect pathogens ${ }^{18}$ and inherent apoptotic processes releasing DNA fragments. ${ }^{16}$ Recent studies further attribute to TLRs the role of regulators of neuronal survival and neuroplasticity, linking their activation to cognitive tasks as well as behavioral outcomes, for example, in Alzheimer's disease. ${ }^{19-21}$ By adopting different modes of action, TLRs can lead to NFKBmediated pro-inflammatory reaction, interferon-mediated stimulation of adaptive immunity and possibly an additional, alternative anti-inflammatory activation of $\mathrm{NF} \kappa \mathrm{B} .^{22,23} \mathrm{An}$ example is Toll-like receptor 9 (TLR9), which discriminates unmethylated $\mathrm{CpG}$ dinucleotides, common in the genomes of most bacteria and DNA viruses as well as in apoptotic host DNA sequences, from the methylated ones in undamaged mammalian DNA. ${ }^{24}$ TLR9-driven pro-inflammatory activation of $N F \kappa B$ may link between the innate and adaptive immune systems by activating $T$ and $B$ lymphocytes through their antigen and co-stimulatory receptors. The fact that $\mathrm{NF} \kappa \mathrm{B}$ also activates an alternative homeostatic pathway, which leads to suppression of pro-inflammatory cytokine production, ${ }^{23,25}$ suggests a possibility of bi-directional effects. In this context, several discriminative subtypes of TLR9 activators can potentiate peripheral innate immune reactions, and are classified into different subgroups. CpG-A ODNs tend to spontaneously form large multimeric aggregates and are therefore retained in the early endosome for relatively long periods, inducing extended activation of the signal-transducing complex and robust type $\alpha$ interferon production. ${ }^{18}$ CpG-B ODNs, however, remain monomeric and accumulate in late endosomes/lysosomes, stimulating B-cell activities, but not interferon $\alpha$ production. ${ }^{16}$ Other ODNs, may assume mixed properties.

Based on the above knowledge, we surmised that if indeed inflammation is functionally implicated in PTSD, the serum cytokine levels in PTSD patients should be significantly associated with the severity of their anxiety symptoms and pathophysiology hallmarks; using cultured cells, predator scent-stressed mice and a series of TLR9-activating and -blocking ODNs, we further challenged the hypothesis that TLR9 can regulate peripheral immune reactions following stress responses, thus restraining the detrimental cognitive and immune consequences of traumatic experiences and avoiding the emergence of PTSD.

\section{Methods}

Human patient recruitments. PTSD patients and healthy volunteers were recruited from the psychiatric outpatient clinics at the Soroka University Medical Center, Beer-Sheva and the Tel Aviv Sourasky Medical Center, Tel-Aviv. A written informed consent approved by the local Ethics Committee was obtained from all participants; PTSD diagnosis was ascertained by a board certified psychiatrist (HS) and scored according to the Clinician-Administered PTSD Scale. ${ }^{26}$ Following recruitment to the study and diagnosis, full medical and psychiatric histories were obtained. Whole-blood samples $(5 \mathrm{ml})$ were drawn into heparincoated plastic tubes, centrifuged (4000 r.p.m., $4{ }^{\circ} \mathrm{C}, 30 \mathrm{~min}$ ), and stored at $-70^{\circ} \mathrm{C}$ until use. Serum was prepared as described. $^{27}$

Magnetic resonance imaging (MRI). Three-dimensional structural MRI scans were acquired on a 1.5-T scanner (Intera, Philips Medical Systems, Best, The Netherlands). Two complete T1-weighted whole brain anatomical scans were collected per subject with the following parameters: repetition time $=15$, echo time $=4.6$, flip angle $=30^{\circ}$, matrix size $256 \times 256$, field of view $25.6 \mathrm{~cm}$, 150 sagittal slices $(1 \times 1 \times 1 \mathrm{~mm}$ resolution). Images were preprocessed, the averaged subject scans sub-cortically segmented and volumes computed manually (pituitary) or by employing Freesurfer release 3.0.2 (Freesurfer@nmr.mgh.harvard. edu; all other regions).

Oligonucleotides. ODN1826, ODN2088 and ODN TTAGGG were purchased from Invivogen (San Diego, CA, USA). mEN101 (5'-ctgcaatattttcttgca* $\left.{ }^{*} c^{*}-3^{\prime}\right)$ (stars denote $2^{\prime}-\mathrm{O}$ methyl groups), complementary to a sequence in exon E2 of mouse AChE mRNA was from Mycrosynth (Balgach, Switzerland). For TLR screening, recombinant HEK-293 cell lines that stably express specific TLR proteins and an NFKB promoter-driven luciferase reporter gene were induced with a ligand specific to the expressed transgenic TLR (TLR2; PAM2 (100 $\mathrm{ng} \mathrm{ml}^{-1}$ ), TLR3; Poly I:C (100 $\left.\mathrm{ng} \mathrm{ml}^{-1}\right)$, TLR4; LPS K12 (100 $\left.\mathrm{ng} \mathrm{ml}^{-1}\right)$, TLR5; Flagellin $\left(1 \mu \mathrm{g} \mathrm{ml}^{-1}\right)$, TLR7; R848 $\left(10 \mu \mathrm{g} \mathrm{ml}^{-1}\right)$, TLR8; R848 $\left(10 \mu \mathrm{g} \mathrm{ml}^{-1}\right)$, TLR9; ODN 2006 (CpG-B) $\left.\left(10 \mu \mathrm{g} \mathrm{ml}^{-1}\right)\right){ }^{22} 20 \mu \mathrm{l}$ ligand was used to stimulate the cells in $200 \mu \mathrm{l}$ reaction volumes.

Animals. Adult TLR9 $-/-$ mice (kindly provided by E. Galun, Jerusalem) and strain-matched wild-type C57/ B6J mice were housed four per cage, at $21 \pm 1^{\circ} \mathrm{C}$, in a 12-h light/dark cycle. All animal studies were approved by the Hebrew University's committee for animal experiments (Ethics number of research: NS-10205-4). See Supplementary Methods for details on the ELISA, Real-time RT-PCR and immunochemistry.

Behavioral paradigms. Mice were placed for $10 \mathrm{~min}$ on well-soiled cat litter. One week after exposure, animals were tested as described ${ }^{28}$ in the elevated plus maze (EPM) and the acoustic startle response paradigms (TLR -/- only). Shortly, mice were placed on the central platform and were allowed to explore the maze for $5 \mathrm{~min}$. For startle response, after a 5-min acclimatization period to a 68-dB white noise, 30 acoustic startle stimuli $(110 \mathrm{~dB}$ white noise of $40 \mathrm{~ms}$ duration with $30 \mathrm{~s}$ or $45 \mathrm{~s}$ inter-trial interval) were delivered (SR-LAB System, San Diego Instruments, San Diego, CA, USA). Habituation was calculated as the percent difference between the first and the last block of stimuli. To avoid orderrelated differences, mice from the different groups were intercalated in the behavioral tests. 
Table 1 Population characteristics

\begin{tabular}{|c|c|c|c|}
\hline Variable & Patients & Control & P-value \\
\hline $\begin{array}{l}n \\
\text { Age, years (s.d.) } \\
\text { Gender, \% (male) } \\
\text { Smoking, \% } \\
\text { Interleukin-1, pg ml } \\
\text { Interleukin-6, pg ml (s.d.) } \\
\text { Acetylcholinesterase, } \mathrm{mm} \mathrm{min}^{-1} \times \mathrm{ml} \text { (s.d.) } \\
\text { Cholinergic status, } \mathrm{mm} \mathrm{min}^{-1} \times \mathrm{ml} \text { (s.d.) }\end{array}$ & $\begin{array}{c}37 \\
37.9(12.4) \\
46.8 \\
57.7 \\
6.2(1.6) \\
11.2(21.7) \\
10.45(0.58) \\
17.43(1.03)\end{array}$ & $\begin{array}{c}37 \\
37.5(11.0) \\
53.2 \\
42.3 \\
5.2(1.0) \\
6.0(3.5) \\
11.19(0.64) \\
18.66(1.08)\end{array}$ & $\begin{array}{l}0.882 \\
0.675 \\
0.115 \\
0.002 \\
0.159 \\
0.230 \\
0.225\end{array}$ \\
\hline $\begin{array}{l}\text { CAPS } \\
\text { Total (s.d.) } \\
\text { Re-experience (IQR) } \\
\text { Avoidance (IQR) } \\
\text { Arousal (IQR) }\end{array}$ & $\begin{array}{c}82.0(25.6) \\
5(4-5) \\
6(3.25-6.75) \\
5(3-5)\end{array}$ & $\begin{array}{l}\text { NA } \\
\text { NA } \\
\text { NA }\end{array}$ & \\
\hline $\begin{array}{l}\text { PSQI (s.d.) } \\
\text { MADRS (s.d.) }\end{array}$ & $\begin{array}{c}23.9(7.2) \\
24.1(10.5)\end{array}$ & $\begin{array}{l}\text { NA } \\
\text { NA }\end{array}$ & \\
\hline
\end{tabular}

Abbreviations: CAPS, Clinician-Administered PTSD Scale; IQR, Interquartile range; MADRS, Montgomery-Åsberg Depression Rating Scale; NA, not applicable; PSQI, Pittsburgh Sleep Quality Index; s.d., standard deviation.

Statistical analysis. Data in the tables are displayed as mean \pm s.d. for the continuous variables and as number of patients and percentage for categorical variables. The oneway Kolmogorov-Smirnov test was used to assess the distributions using SPSS/WIN (version 15.0, SPSS, Chicago, IL, USA). The different biomarkers for patients and controls were compared by Student's $t$-test for normally distributed variables and the Mann-Whitney U-test for non-normally distributed variables (Presented as median and Interquartile range). Correlations between parameters were determined by the Pearson's correlation test, a $P$-value of $<0.05$ was considered statistically significant (Table 1).

\section{Results}

Serum inflammatory markers correlate with symptoms severity and volumetric brain changes in PTSD patients. To test for inter-relationships between serum inflammatory biomarkers and the severity of PTSD symptoms, we recruited both male (53\%) and female (47\%) PTSD patients and matched controls for a retrospective study. The patient demographics are summarized in Table 1. The mean age in the PTSD and control groups was 37.9 (range 18-62) and 37.5 (22-59), respectively. PTSD diagnosis was confirmed using the Clinician-Administered PTSD Scale. This included re-experience, avoidance and arousal scores, each assessing a major symptomatic axis of PTSD. ${ }^{26}$ Patients also presented co-morbid depression in the Montgomery-Åsberg Depression Rating Scale (MADRS). ${ }^{29}$ Compatible with previous reports, ${ }^{30,31}$ patients presented higher IL-1 $\left(6.2 \pm 1.6\right.$ vs $5.2 \pm 1.0 \mu \mathrm{gl}^{-1}$ serum, $\left.P=0.002\right)$, but not IL-6 (11.2 \pm 21.7 vs $6.0 \pm 3.5 \mu \mathrm{gl}^{-1}$ serum, $\left.P=0.159\right)$, which presented higher variability. Nevertheless, given the reports on the increase in PTSD of both IL-1 and IL-6, we used the summated serum IL1 $\beta$ and IL6 levels (designated 'inflammatory load', (Figure 1a)) to challenge the possibility that peripheral inflammation is correlated with PTSD symptoms severity. When divided into high and low inflammatory load by splitting the group in the median
(Figure 1a), patients with high inflammatory load $(n=9)$ showed increased re-experiencing $(P<0.014$, Figure $1 \mathrm{~b})$, arousal $(P<0.022)$, overall Clinician-Administered PTSD Scale $(P<0.05)$ and MADRS $(P<0.02)$ scores compared with PTSD patients with low inflammatory load $(n=10)$. Avoidance scores $(P<0.19)$ and the unrelated Pittsburgh Sleep Quality Index score ${ }^{32}$ showed no correlation to cytokine concentration in the blood (Figure 1b), possibly limiting the impact of their enhanced inflammation to their autonomic response, but not behavioral manifestations that are conditioning dependent.

Selective reduction in hippocampal volume is an established neuro-anatomical marker of PTSD. ${ }^{32,33}$ Magnetic Resonance Imaging (MRI) tests, which were available for several of the examined PTSD patients, depicted reduced hippocampal volume, which was inversely correlated to their serum IL $1 \beta$ levels $(n=5, r=-0.966, P<0.008$, Pearson's correlation, Figure 1c1), though not to IL6 levels $(r=-0.848$, $P=0.07$ ). No correlations were found between IL1 $\beta$ levels and the volume of other brain structures, such as the cerebral cortex ( $r=0.326, P=0.593$; Figure 1c3), amygdala (AMG), thalamus, pallidum, brain stem and ventricles, attesting to the specificity of the observed changes. Variable pituitary volumes (Figure 1c2, $r=50, P=0.391$ ) might reflect hormonal perturbations.

TLR9 activation ameliorates anxiety responses. The apparent association between PTSD symptoms severity and peripheral inflammation raised the question if peripherally administered $\mathrm{CpG}$-including oligonucleotide activators of TLR9 and $\mathrm{NF} \kappa \mathrm{B}$, or other ODNs modulators of inflammation can modulate post-traumatic inflammation. We first exposed mice to the predator scent-mediated stress paradigm $^{28}$ and treated them intraperitoneally (i.p.) with AChE antisense ODN mEN101, which by suppressing AChE should elevate acetylcholine levels, facilitating the cholinergic blockade of inflammation. ${ }^{15}$ Of note, mEN101was shown to suppress immediate anxiety when i.p. administered to predator scent-stressed mice ${ }^{34}$ and to rapidly reduce both AChE and anxiety symptoms when injected to the hippocampus of foot 

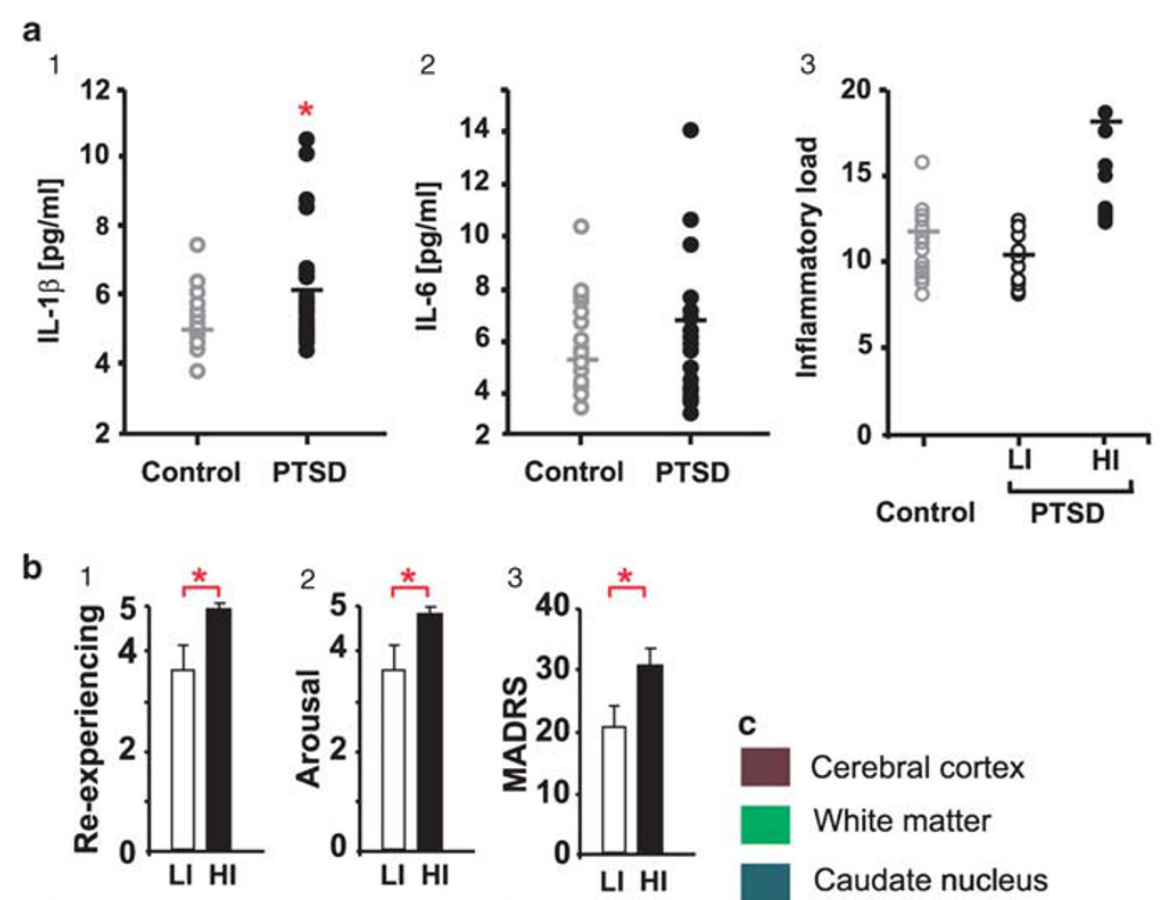

c
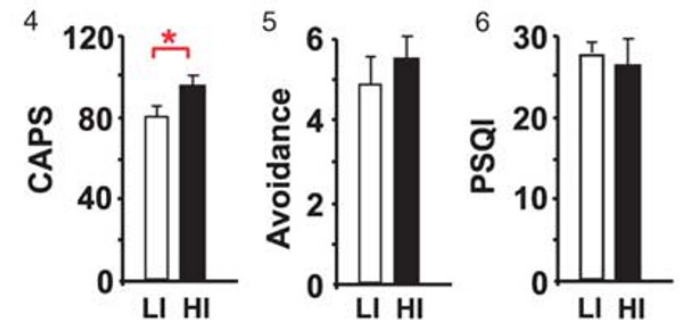

Cerebral cortex
White matter
Caudate nucleus
Putamen
Pallidum
Hippocampus
Cerebellar cortex
Cerebellar white matter
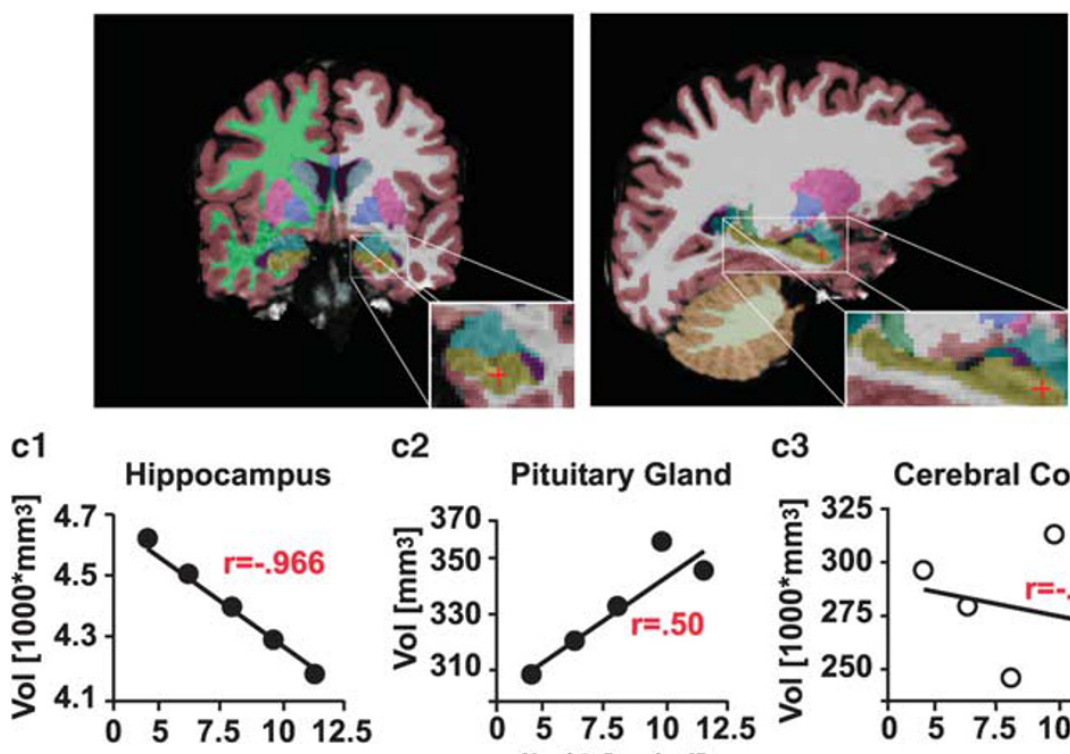

c2

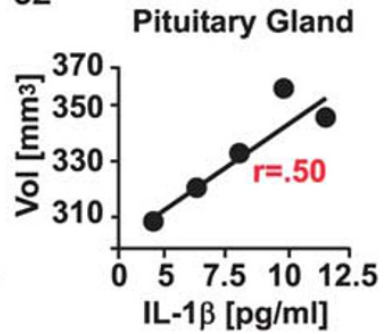

c3

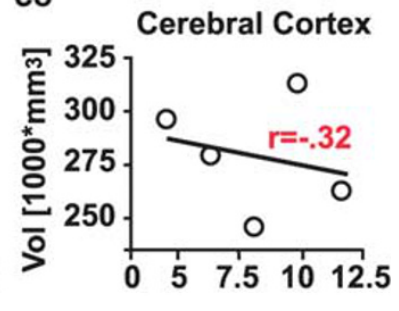

Figure 1 Inflammatory markers are correlated with Post-traumatic stress disorder (PTSD) severity. (a) Inflammatory markers are increased in PTSD patients compared with controls matched by age and gender. (1) Interleukin (IL) 1 $\beta$. (2) IL6. (3) Inflammatory load (summated IL1 $\beta$ and IL6 levels) in PTSD patients, divided into those with higher (HI) and lower (LI) loads (see text for details). (b) PTSD behavioral symptoms are increased in patients with high inflammatory load. (1) Clinician-Administered PTSD Scale (CAPS) re-experience score. (2) CAPS arousal score. (3) Montgomery-Åsberg Depression Rating Scale (MADRS). (4) CAPS total score. (5) CAPS avoidance score. (6) Pittsburgh Sleep Quality Index (PSQI). (c) IL1 $\beta$ correlates to PTSD patients' hippocampal volume. Top Scheme: Coronal and saggital image showing the boundaries of the measured structures: (c1), (c2) and (c3). IL1 $\beta$ levels are inversely correlated to average hippocampal volume and positively correlated to pituitary gland volume, but not to the cortical volume of PTSD patients. ( ${ }^{\star} P<0.05$, one-tailed $t$-test.) 
shock-stressed mice. ${ }^{35}$ The current study's aim was to test the long-term effects of ODN mEN101 and its human ortholog BL$7040^{36}$ on inflammation, anxiety and the inter-relationships between them.

Tested ODNs or saline were i.p. injected to predator scentexposed mice for four consecutive days starting at exposure. On the 7th day, pre-stressed mice with or without ODN treatments were subjected to anxiety feature tests in the EPM (Figure 2a). Stressed mice spent less time in the open arms and entered them less frequently compared with naïve mice $(n=11) \quad\left(F_{6,111}=13.23, \quad P<0.05 ; \quad F_{6,111}=15.42\right.$, one-way

a

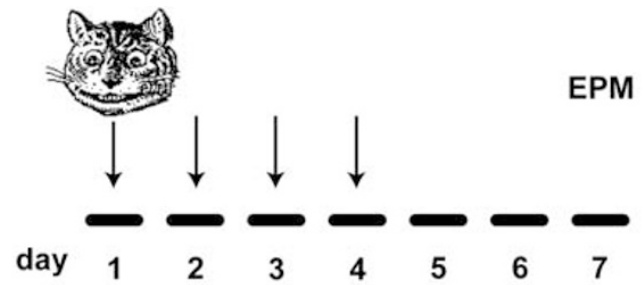

b

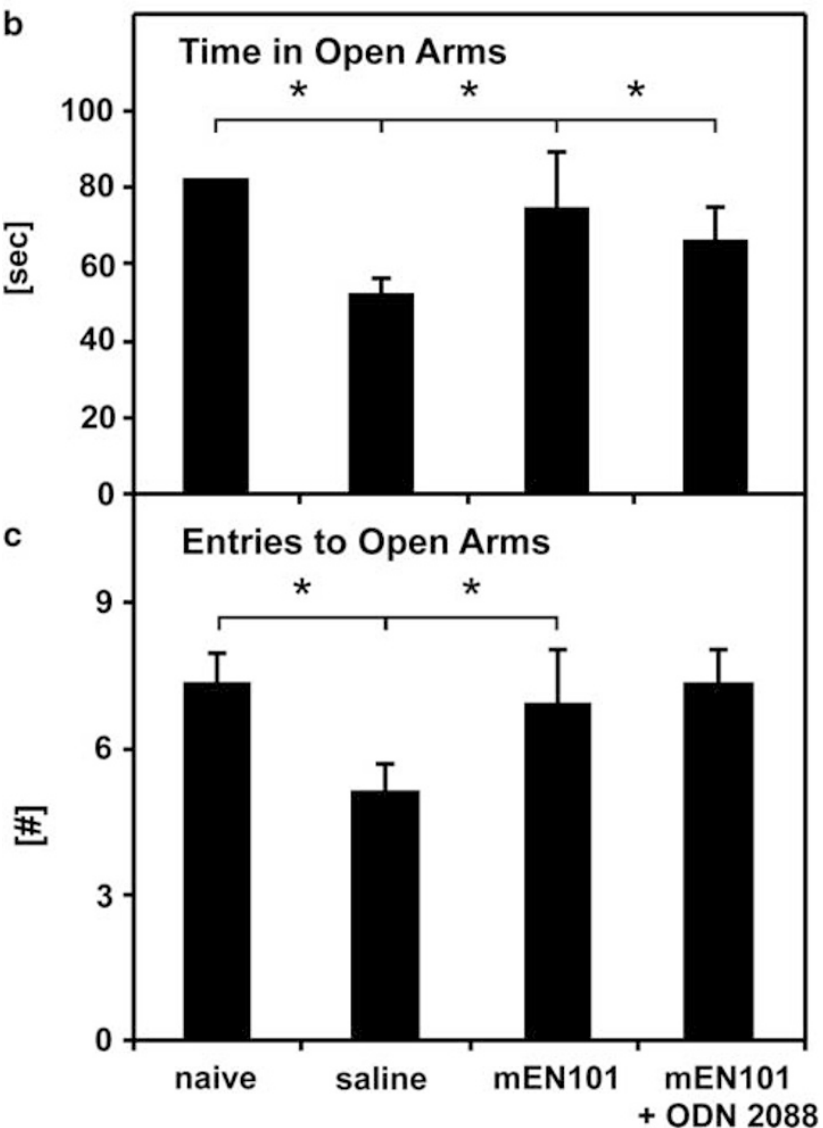

Figure 2 mEN101-mediated activation of Toll-like receptor 9 (TLR9) ameliorates predator scent stress effects. (a) Predator scent stress paradigm. Seven days post-stress mice i.p. injected immediately before and consecutive 4 days after stress were subjected to EPM tests. (b) TLR9 activation is anxiolytic. On day 7, cat scent exposed, saline injected C57B mice showed poorer EPM scores than naïve animals. Injection of $50 \mathrm{\mu g} \mathrm{kg}^{-1} \mathrm{mEN101}$ ameliorated anxiety as reflected by the length of time spent in open arms. These effects were abolished by co-injection of $500 \mathrm{\mu g} \mathrm{kg}^{-1}$ of the TLR9 blocker ODN 2088. (c) Entries to open arms. In this measure as well, mEN101 ameliorated anxiety; however, excess ODN 2088 did not change the no. of entries to open arms. Stars note statistically significant differences between the marked groups. analysis of variance and Tukey post hoc test) (Figures $2 \mathrm{~b}$ and c). By day 7 post-stress, mice i.p. injected with $50 \mu \mathrm{g} \mathrm{kg}^{-1}$ mEN101 showed diminished stress-induced anxiety scores compared with stressed mice $(n=27 ; P<0.001, P<0.01$, time in open arms and entry to open arms) (Figures $2 b$ and $c$ ). To test if this anxiolytic effect was co-mediated by TLR9, we co-administered mEN101 with excess $\left(500 \mu \mathrm{g} \mathrm{kg}^{-1}\right)$ of the specific TLR9-inhibitor ODN2088 $(n=7)$. Co-treated mice spent more time than stressed ones in the open arms $(P<0.001$, Figure $2 \mathrm{~b})$, however, their number of entries to the open arms remained unchanged (Figure $2 \mathrm{c}$ ), suggesting that blocking TLR9 interferes with the mEN101 anxiolytic effects, but does not prevent it completely.

TLR9 activation abolishes delayed neuronal activation in stress-related brain nuclei. Acute psychological stressors increase neuronal activity in several stress-related brain nuclei. ${ }^{1,2,5}$ Two hours following stress exposure, predator scent-stressed FVB/N mice $(n=3)$ showed increased numbers of c-fos-stained neurons compared with naïve controls in the hypothalamic paraventricular nucleus, the hippocampal CA3 region and the AMG $(P<0.05$ for all, Mann-Whitney U-test). Next, we exposed animals to predator odor with or without mEN101 treatment, performed EPM and startle anxiety tests 1 week later, and tested the same regions in brains from animals killed $2 \mathrm{~h}$ afterwards. Previously stressed mice $(n=3)$ showed enhanced neural activation, reflected by c-fos immunohistochemistry, compared with naïve controls $(n=4)$. Elevated c-fos was observed in the paraventricular nucleus, CA3 and AMG ( $P<0.02$ for all), amongst other brain areas. Administered mEN101 completely abolished these delayed c-fos increases $(P<0.05$ for all) (Figures $3 a$ and b) $(n=4)$. mEN101 thus efficiently prevented the long-term consequences of predator stress. All of the stressed and salinetreated animals showed more stained neurons per analyzed area than any of the naïve ones, and all of the mEN101treated animals showed significantly less stained neurons than any of the saline-treated ones.

Anxiolytic TLR9 activation exerts systemic anti-inflammatory effects. Four days following exposure, stressed FVB/N mice $(n=4)$ showed increased IL-6 serum levels $(P<0.02$, Mann-Whitney test), but their serum IL-1 $\beta$ was insignificantly elevated compared with saline treated ones $(P<0.15) \quad(n=5$, Figure 3c). Compatible with previous reports, which showed stress-induced elevation of $\mathrm{IL}-1 \beta^{7}$ and with thee anxiolytic effects of mEN101, its administration decreased the observed post-stress levels of IL-6 $(P<0.004)$ and IL-1 $\beta \quad(n=4, \quad P<0.02$; Figure $3 c)$. Similarly, adding mEN101 and well established TLR9 activators and blocker ODNs to cultured RAW macrophages identified mEN101 as a TLR9 activator with low affinity and mixed properties (Supplementary Material and Supplementary Table 1).

TLR9 controls gene expression changes in stressrelated brain areas. Peripherally-produced cytokines penetrate the brain, activate interleukin receptors located in different brain areas and may induce stress-related symptoms. ${ }^{37,38}$ We hypothesized that, by abolishing cytokine upregulation, 
a
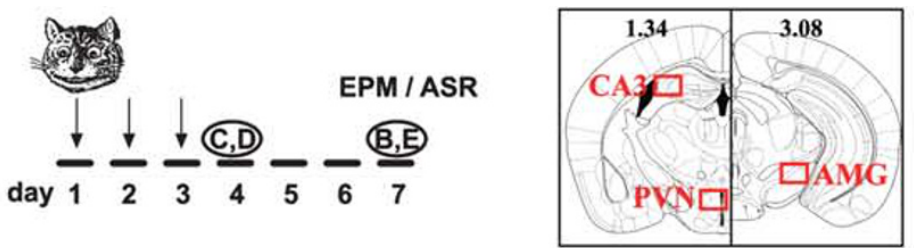

b
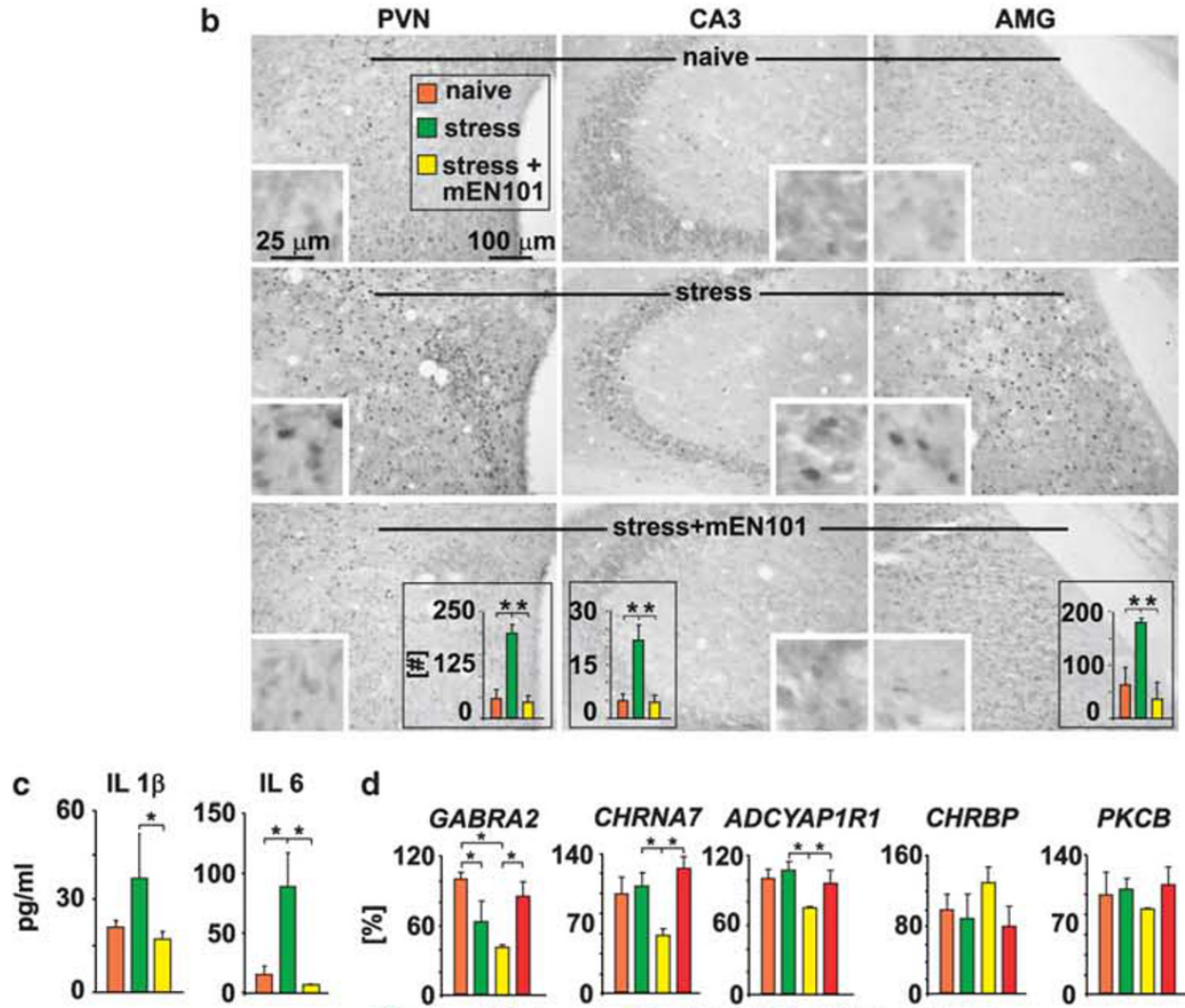

d GABRA2 CHRNA7 ADCYAP1R1 CHRBP PKCB

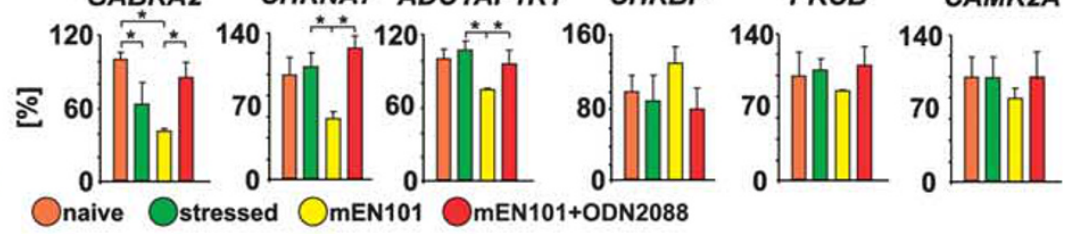

e

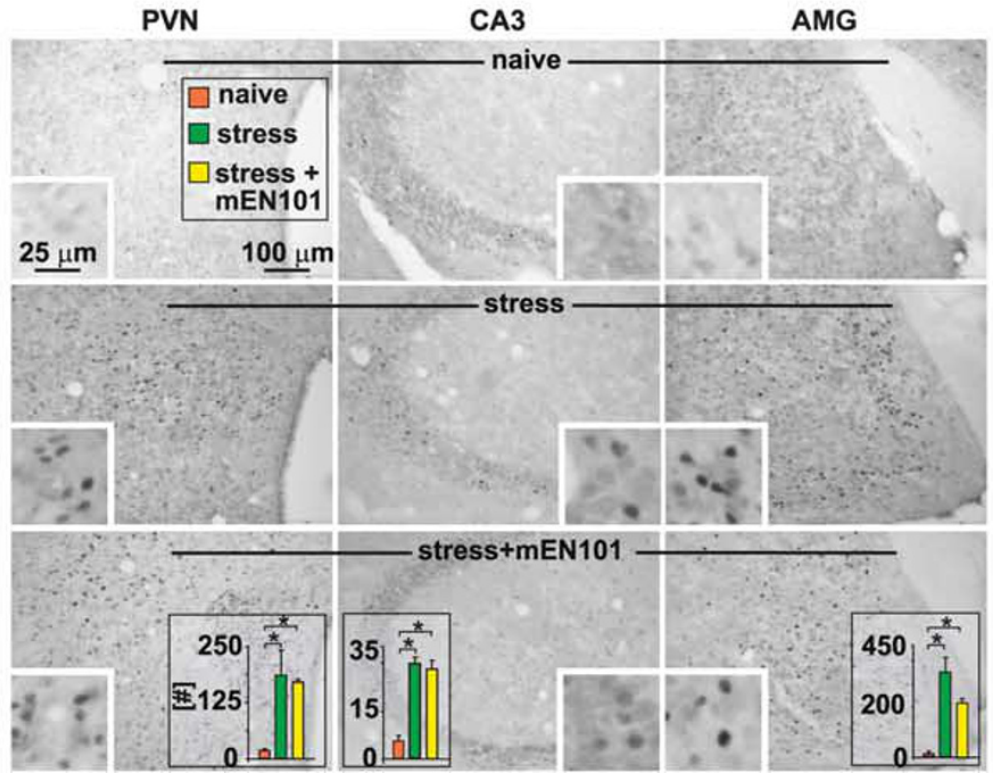


TLR9 activation could prevent at least part of the stress-related changes in gene expression. ${ }^{39}$ Therefore, we searched for modifications in anxiety-related transcripts in the hippocampus, a major structure of the limbic system. The Mouse Genome Initiative (http://www.informatics.jax.org/) reports 259 genes related to anxiety phenotypes. Of those, 11 hippocampalexpressed genes were reported by others as involved in abnormal EPM reactions. Four days following stress exposure, we tested the expression levels of these transcripts in naïve and stressed mice, mEN101-treated or untreated $(n=4$ each group). mEN101-mediated TLR9 activation reduced the hippocampal expression of 3 out of these 11 EPM-related transcripts in stressed mice, namely the GABA receptor $\alpha 2$ subunit transcript, the nicotinic receptor subunit $\alpha 7$ (CHRNA7) and adenylate cyclase activating polypeptide 1 receptor $(P<0.001, P<0.03$ and $P<0.03$ one-tailed $t$-test, respectively). Furthermore, TLR9 blockade by ODN2088 reversed these changes (Figure 3d). Other anxiety-related genes, including the corticotrophin releasing hormone binding protein (CHRBP), which controls HPA axis activation, ${ }^{40}$ and the fearconditioning related genes protein kinase $\mathrm{C} \beta(P K C \beta)^{41}$ and calcium/calmodulin-dependent protein kinase $2 \alpha(C A M K 2 A)^{42}$ showed no significant changes (Figure 3d).

The early growth response gene 1 (egr1) is a transcription factor activated by interleukin receptors, that operates as a central mediator of inflammation in the brain. ${ }^{43}$ Correspondingly, pre-stressed mice showed higher egr1 expression than naïve mice in brain nuclei expressing the $\mathrm{IL}-1 \beta$ and IL-6 receptors (for example, CA3 and AMG), as well as in the paraventricular nucleus. TLR9-mediated abolishment of peripheral cytokines should principally block interleukin receptor activation and subsequent egr1 activation in the brain. ${ }^{10,38}$ Compatible with this prediction, peripheral TLR9 activation by mEN101-abolished egr1 increases in the paraventricular nucleus and AMG, however, it had no effect in the CA3 region (Supplementary Figure 1). Of note, a single mEN101 dose administered immediately before the stressor did not modify this response (Figure $3 e$ ), suggesting that within this timeframe, mEN101 does not diminish the threat perception and the acute reaction induced by potent stressors.

Endogenous TLR9 activity modulates anxiety-related gene expression and behavior. Our results demonstrated that peripheral immune signals, which are restrained or boosted by TLR 9 activation signals outside the brain are causally involved with the processing of psychological stressors. This raised the question if consistent TLR9 activity contributes to stress-related changes in brain gene expression and in behavior. To test if this was the case, we compared C57/B6J mice with genetically ablated TLR9 ${ }^{44}$ to strain-matched controls under baseline and stress conditions using both EPM and acoustic startle response (Figure 4a), and quantified their EPM-associated hippocampal transcripts.

In behavioral tests, naïve TLR9 $-/-$ mice $(n=6)$ exhibited anxiety-induced increased EPM scores $(P<0.002$, one-tailed $t$-test), reflecting greater basal anxiety than naïve C57/B6J animals $(n=16)$. The TLR9 $-/-$ startle response, but not startle habituation, was similar to that of C57/B6J mice $(P<0.07$, Figure $4 \mathrm{c})$, suggesting intact motor reflexes; ${ }^{45}$ nevertheless, the general anxiety index $(\mathrm{Al})^{46}$ for TLR9 -/mice was significantly increased $(P<0.035)$ (Figure $4 d$ ), suggesting that inherent depletion of TLR9 reactions modifies anxiety-related behavior.

Hippocampi from naïve TLR9 -/- mice showed upregulation of GABA receptor $\alpha 2$ subunit transcript and downregulation of CHRBP $(P<0.01$, one-tailed $t$-test $)$, both predicting increased HPA axis activation compared with naïve C57/B6 mice ( $n=6$, in each group). ${ }^{40}$ Parallel decreases in PKC $\beta$ transcripts $(P<0.05)$ suggested impaired contextual fear learning. ${ }^{41}$ Other tested stress-related transcripts (for example, CHRNA7 and CAMK2A) were unaltered in TLR9 -/- hippocampi, attesting to the selectivity of the observed differences (Figure 4b) and compatible with the minimal changes in these transcripts in stressed C57BJ mice (Figure 3d). Furthermore, unlike FVB/N ${ }^{35}$ and C57/B6J mice $^{34}$ (and the current report), TLR $9-/-$ mice were totally refractory to daily injections of $500 \mu \mathrm{g} \mathrm{kg}^{-1} \mathrm{mEN} 101$, a dose anxiolytic in similar short-term stress models of C57B6J background $^{34}$ (Supplementary Figure 2).

Next, we repeated the predator scent stress experiment (Figure 5a) using the human paralog of mEN101, BL-7040 (previously called hEN101), which was found to be therapeutically effective in patients with the inflammation-associated autoimmune disease myasthenia gravis. ${ }^{47}$ Stressed C57B mice injected with saline predictably entered less frequently into the open arms and spent shorter time there than their naïve peers. On the contrary, they spent more time in the closed arms $\left(n=10\right.$ for all groups $F_{6,69}=3.97, P<0.001$; $F_{6,69}=12.09, P<0.0003 ; F_{6,69}=10.07, P<0.001$, one-way analysis of variance and Tukey post hoc test) (Figure $5 \mathrm{~b}$ ).

Figure 3 Toll-like receptor 9 (TLR9) activation suppresses delayed stress-related processes in brain and periphery. (a) The experimental paradigm. On day 4, serum was removed for measuring interleukin (IL) $-1 \beta$ and IL-6 levels (C) and hippocampal RNA was prepared for measuring changes in gene expression (D). On day 7, brain sections were prepared for $\mathrm{c}$-fos $(\mathrm{B})$ and egr-1 labeling $(\mathrm{E})$. (b) TLR9 activation prevents delayed increases in the numbers of cells presenting c-fos induction in response to mild stress. Columns: On day 7, increased c-fos expression was found in paraventricular nucleus (PVN), CA3 and amygdala (AMG) of pre-stressed, but not stressed and mEN101-treated mice relative to naïve controls. ( ${ }^{*} P<0.05$, Mann-Whitney U-test). (c) TLR9 activation abolishes stress-induced IL1 $\beta$ and IL6 increases ( ${ }^{*} P<0.02$, Mann-Whitney U-test). (d) The elevated plus maze (EPM) malfunctioning-related transcripts GABA receptor $\alpha 2$ subunit transcript (GABRA2), CHRNA7, adenylate cyclase activating polypeptide 1 receptor 1 (ADCYAP1R1), but not PKCB, CHRBP and calcium/calmodulin-dependent protein kinase $2 \alpha$ (CAMK2A), were downregulated following stress, upregulated following mEN101 injection and reduced to control levels under co-administration of the TLR9 blocker ODN2088 $\left({ }^{*} P<0.05\right.$, one-tailed $t$-test). (e) TLR9 activation does not inhibit immediate stress reactions. Brain sections were assayed $2 \mathrm{~h}$ after acute stress and $\mathrm{c}$-fos expression was quantified by immunohistochemical staining followed by counting labeled nuclei. Two hours after acute stress exposure, increased c-fos expression was found in the PVN, CA3 and AMG of both untreated (2) and mEN101-treated mice (3) relative to naïve controls (1). Columns: No. of labeled nuclei per section $\left({ }^{*} P<0.05\right.$, Mann-Whitney $U$-test). Increased egr-1 expression in PVN, CA3 and AMG of stressed mice $(2,3)$ relative to naïve controls (1). Note that TLR9 activation by mEN101 (3) abolished such increases in PVN and AMG, but not in CA3. One set of sections out of 3 reproducible ones. 
a

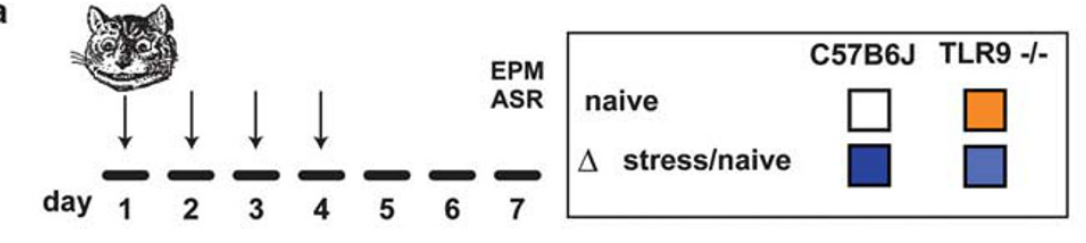

b
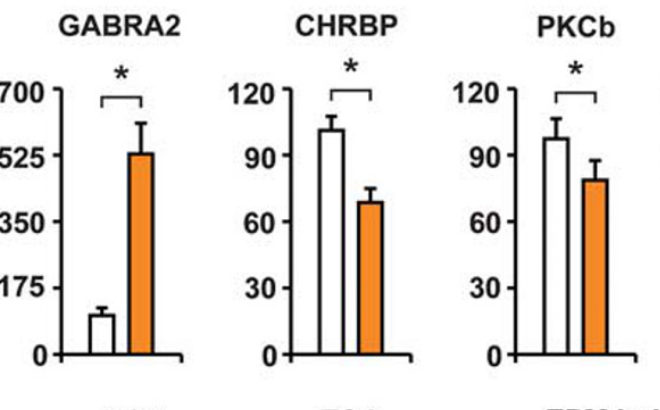

CAMK2A

CHRNA7

c

EOA

TOA
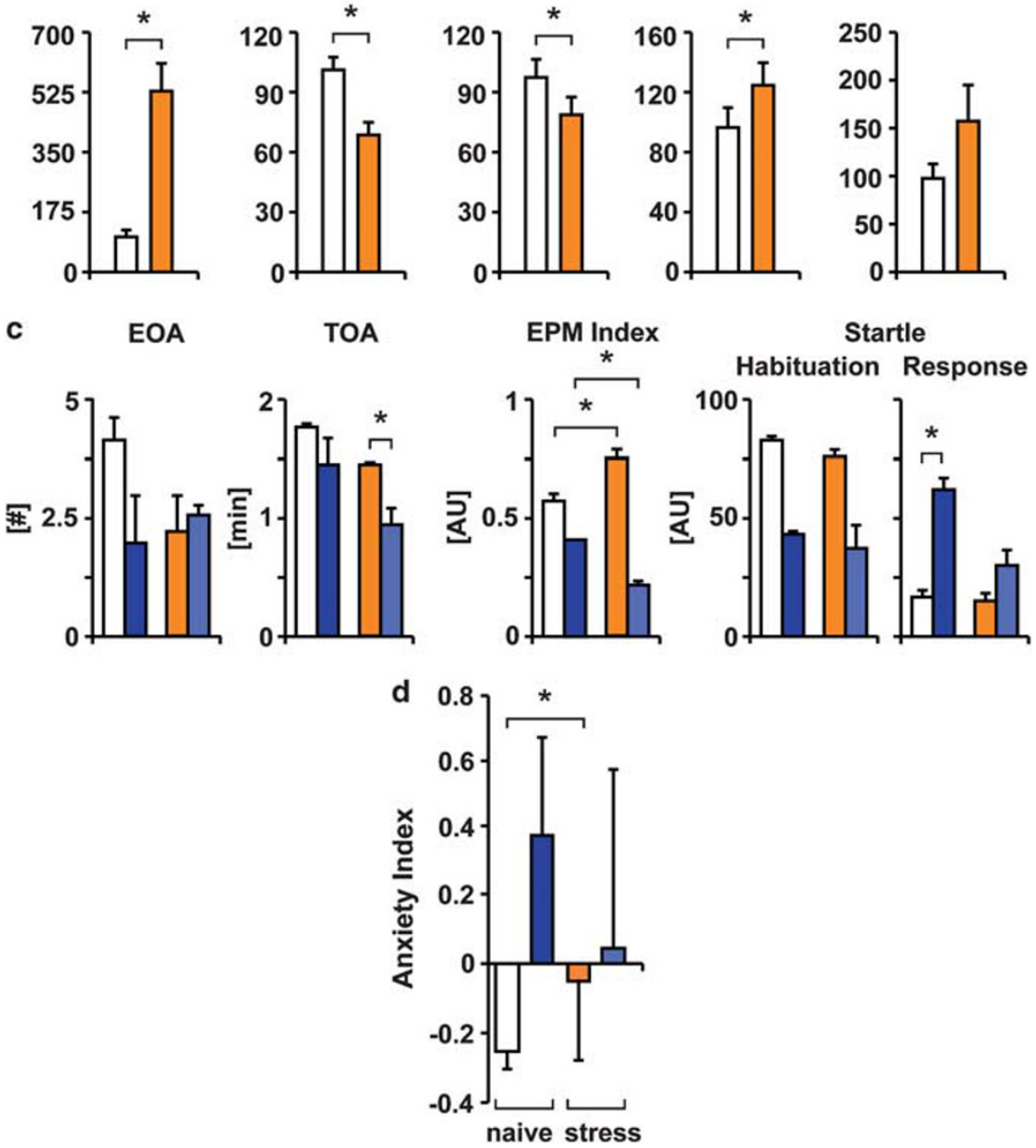

Figure 4 Toll-like receptor 9 (TLR9) - /- mice exhibit changes in hippocampal gene expression, accentuated basal anxiety and subdued stress responses. (a) The experimental paradigm. C57/B6 TLR9 -/- mice and strain-matched controls were tested as in Figures 1 and 2. (b) Naïve TLR9 -/- mice showed inherently different transcript levels for the anxiety-related hippocampal GABA receptor $\alpha 2$ subunit transcript (GABRA2), CHRBP, and PKCB relative to matched controls $\left({ }^{*} P<0.05\right.$, one-tailed $t$-test). Calcium/calmodulin-dependent protein kinase $2 \alpha$ (CAMK2A) and CHRNA7 transcripts were not altered. (c) TLR9 - I- mice showed inherited differences in stress responsiveness. Naïve TLR9 $-/$ - mice presented higher anxiety than matched C57/B6 controls, but their score differences after stress exposure were smaller ${ }^{*} P<0.05$, one-tailed $t$-test and Mann-Whitney U-test). (d) Anxiety Index of C57/B6 and TLR9 $-/-$ mice under different experimental conditions.

Importantly, stressed mice injected for four consecutive days with $50 \mu \mathrm{g} \mathrm{kg}^{-1}$ of the NFKB activator ODN1826, levels of which induce robust inflammatory effects, ${ }^{16}$ showed stress-characteristic performance similar to that of stressed non-injected mice. In contrast, the anti-human AChE ODN BL-7040 (hEN101), ${ }^{34,36}$ when daily i.p. injected at $50 \mu \mathrm{g} \mathrm{kg}^{-1}$ diminished stress-induced anxiety scores compared with stressed mice $(P<0.002$, for EOA, TOA and TCA).

$\mathrm{BL}-7040$ is targeted towards human AChE mRNA, which differs from mouse AChE mRNA in the target sequence of the tested ODN by 4 out of 20 nucleotides $5^{1}$-CTGCc-Ac-G
TTC-TCc-TGCACC-3', lower-case nucleotides different. This suggested that BL-7040 is unlikely to exert simple antisense effects in i.p. injected mice. When we co-administered BL-7040 with excess $\left(500 \mu \mathrm{g} \mathrm{kg}^{-1}\right)$ of the specific TLR9inhibitor ODN2088, ${ }^{16}$ the BL-7040 anxiolytic effect was totally abolished $(P<0.003, P<0.007, P<0.004$, for EOA, TOA and TCA, respectively). However, when injected alone, ODN2088 exerted no anxiolytic effect (Figure $5 \mathrm{~b}$ ), indicating that transient TLR9 blockade does not affect anxiety and suggesting that the TLR9-mediated anxiolytic effect involved alternative TLR9 activation rather than blockade. Also, both 
mEN101 and BL-7040 reduced AChE activity in the serum of treated mice, suggesting enhanced blockade of inflammation due to ACh elevation ${ }^{27,48}$ (Supplementary Material).

a
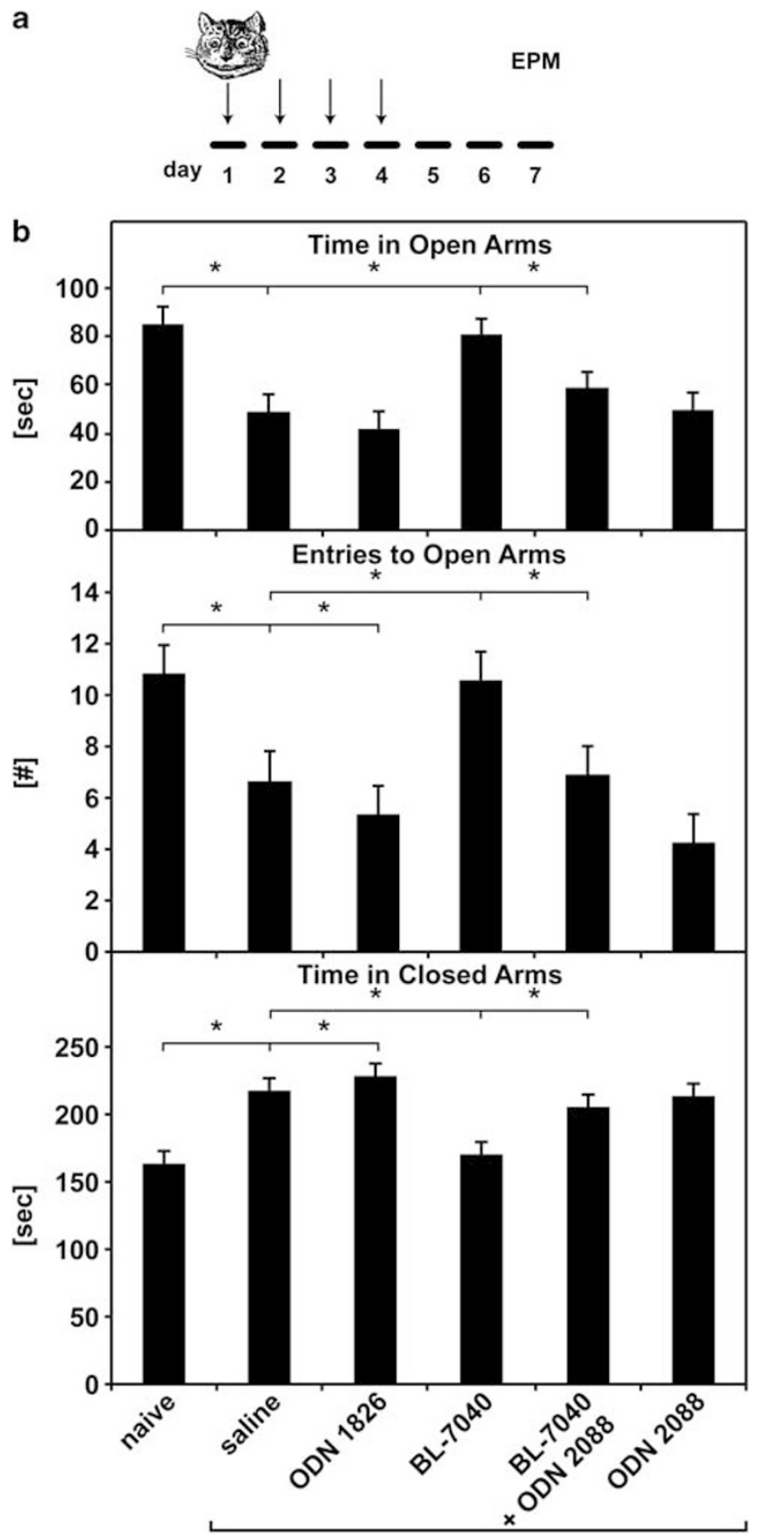

Predetor scent stress

Figure 5 BL-7040-mediated activation of Toll-like receptor 9 (TLR9) ameliorates long-term stress effects. (a) Predator-scent stress paradigm. Seven days post-stress animals i.p. injected immediately before and 4 days after stress were subjected to EPM tests. (b) BL-7040-mediated TLR9 activation is anxiolytic. On day 7, cat scent-exposed, saline-injected C57B mice showed poorer EPM scores than naïve animals. Injection of $50 \mu \mathrm{g} \mathrm{kg}^{-1}$ ODN1826 increased anxiogenic behavior compared with saline injection. Inversely, $50 \mathrm{\mu g} \mathrm{kg}^{-1}$ of $\mathrm{BL}-7040$ ameliorated anxiety. These effects were abolished by co-injection of $500 \mathrm{\mu g} \mathrm{kg}^{-1}$ of ODN2088 (EN + 2088). Injection of $500 \mu \mathrm{g} \mathrm{kg}^{-1}$ of ODN2088 alone did not affect acute stress effects.

\section{Discussion}

Studying the underlying causes and consequences of posttraumatic inflammation, we found association of serum interleukin-1 $\beta$ increases with symptoms severity and volumetric hippocampal changes in PTSD patients, suggesting functional involvement of $N F \kappa B$. To challenge this implication, we manipulated both inflammation and anxiety in predator scent-stressed mice by peripheral administration of both mEN101 and BL-7040, which emerged as selective TLR9mediating activators of the alternative $N F \kappa B$ pathway. Our findings identify peripheral TLR9-mediated activation of the alternative NFKB pathway as a continuous surveillance mechanism for preventing post-traumatic inflammation and anxiety, suggesting that failed interception of the vicious cycle linking stress reactions with peripheral inflammation is a risk for PTSD. Supporting this notion, the mouse BL-7040 paralog mEN101 prevented post-traumatic hippocampal transcript modifications and $\mathrm{c}$-fos and EGR1-mediated neuronal activation. Correspondingly, TLR9-/- mice were BL-7040 refractory and presented unprovoked anxiety-characteristic behavior and hippocampal transcripts. Thus, both gain and loss of inflammatory features in experimental mice supported causal involvement for peripheral TLR9-mediated surveillance in PTSD protection.

Psychological states are primarily processed by the brain, which focused therapeutic development in this field on agents directly affecting neural function. Such is the case of the GABAergic agonists and drugs affecting monoamine neurotransmitter metabolism. ${ }^{49}$ In contradistinction, our current work indicates a peripherally-initiated cascade that breaks the feed-forward loop between the peripheral inflammatory system and the brain to restrain subsequent stress impacts. This further calls for specific precautions regarding potentially detrimental psychological side effects of immune-stimulating doses of TLR9 activators, ${ }^{16}$ while representing a novel approach for the development of anxiolytic compounds and offering new indications for known TLR9 agonists under clinical trials.

The observed serum suppression by BL-7040 of poststress IL-1 $\beta$ and IL- 6 emerges as one of the first steps in the anxiolytic cascade. Slightly increased levels of peripheral cytokines can both stimulate stress-related nuclei ${ }^{7,29}$ and facilitate the consolidation of fear memories. 8,31 Therefore, cytokine decrease following TLR9 activation may mediate TLR9 stress-suppressive effects. Moreover, the brain penetration capacities of peripheral cytokines may explain the observed increase in egr1 expression, and TLR9-mediated immune regulation could block egr1 increase by mitigating cytokine production.

The peripheral administration mode of the employed TLR9 agonists further suggests initiation of their psychoactive effects in peripheral TLR9-expressing cells. Compatible with this prediction, ODNs fail to cross the BBB owing to their high polarity, which is a major obstacle for their use as neuroactive agents. ${ }^{50}$ In most performed studies only a tiny $(<0.1 \%)$ portion of the injected ODNs was found in brain tissue, even when much higher doses than that used by us were delivered. ${ }^{50}$ The TLR9-mediated effects of ODN1826 and ODN2088 are reported elsewhere. ${ }^{16}$ Correspondingly, 
suppression of the mEN101 anxiolytic effects and hippocampal transcript changes in mice by the specific TLR9 blocker ODN2088, and TLR9 - /- mice being refractory to the mEN101 anxiolytic effect (the current report) both attests to the TLR9-mediation of mEN101. Compared with their strainmatched controls, TLR9 -/- mice further showed a bimodal behavioral imbalance of increased basal anxiety and diminished reaction to acute stressors, suggesting that physiological TLR9 activation affects the ventral angular bundlebasolateral amygdala pathway. ${ }^{29}$ In contrast, the unchanged acoustic startle response performance of TLR9 -/- mice suggests normal central amygdala-periaqueductal gray matter connectivity. ${ }^{31,51}$ Inherited Impairments in TLR9 functioning may be pursued as causing parallel damages in humans.

The autonomic nervous system releases ACh continuously from the vagus, thereby activating its receptors, especially $\mathrm{nAChR} \alpha 7$ in peripheral blood mononuclear cells, suppressing production of pro-inflammatory cytokines. ${ }^{48} \mathrm{~A}$ finelytuned balance between this brain-to-body signaling process and the TLR9-mediated control of $N F \kappa B$ regulation of pro-inflammatory cytokine secretion is essential for proper regulation of this autonomous function. Our findings of co-regulation by TLR9 of cholinergic and inflammatory functions highlight a previously non-perceived powerful mechanism for monitoring anxiety, distinct from the $\mathrm{nA}$ ChR $\alpha 7-$ mediated cholinergic suppression of inflammatory processes. $^{16}$ In conclusion, we showed that moderate activation of TLR9 suppresses peripheral levels of brainpenetrating cytokines and minimizes the behavioral consequences of acute stress exposure. To the best of our knowledge, this is the first anxiolytic indication both for peripherally acting drugs and for aptamers at large, adding a previously unforeseen range of translational psychiatry uses for TLR9 therapeutics.

\section{Conflict of interest}

The authors declare no conflict of interest.

Acknowledgements. The authors are grateful to Drs E Galun and A Gilboa-Geffen for the TLR9-1- mice and for assistance with experiments. This study was supported by the German Research Foundation Trilateral Cooperation Program, the Gatsby Foundation and The Israel Science Foundation Legacy Grant No. 378/11 and GZ and SB were supported by an ELSC pre-doctoral fellowship, GS, by a Levy Eshkol post-doctoral fellowship and SS-T by an ELSC post-doctoral fellowship. BL-7040 program has been licensed to BioLineRx for future development.

1. McEwen BS, Gianaros PJ. Stress- and allostasis-induced brain plasticity. Annu Rev Med 2011; 62: 431-445

2. de Kloet ER, Joels M, Holsboer F. Stress and the brain: from adaptation to disease. Nat Rev Neurosci 2005; 6: 463-475.

3. Banks WA, Kastin AJ. Blood to brain transport of interleukin links the immune and central nervous systems. Life Sci 1991; 48: PL117-PL121.

4. Cohen H, Geva AB, Matar MA, Zohar J, Kaplan Z. Post-traumatic stress behavioural responses in inbred mouse strains: can genetic predisposition explain phenotypic vulnerability? Int J Neuropsychopharmacol 2008; 11: 331-349.

5. Sapolsky RM, Romero LM, Munck AU. How do glucocorticoids influence stress responses? Integrating permissive, suppressive, stimulatory, and preparative actions. Endocr Rev 2000; 21: 55-89.

6. Spivak B, Shohat B, Mester R, Avraham S, Gil-Ad I, Bleich A et al. Elevated levels of serum interleukin-1 beta in combat-related posttraumatic stress disorder. Biol Psychiatry 1997; 42: $345-348$.
7. Nguyen KT, Deak T, Owens SM, Kohno T, Fleshner M, Watkins LR et al. Exposure to acute stress induces brain interleukin-1beta protein in the rat. J Neurosci 1998; 18: 2239-2246.

8. Sternberg EM. Neural regulation of innate immunity: a coordinated nonspecific host response to pathogens. Nat Rev Immunol 2006; 6: 318-328.

9. Goshen I, Kreisel T, Ben-Menachem-Zidon O, Licht T, Weidenfeld J, Ben-Hur T et al. Brain interleukin-1 mediates chronic stress-induced depression in mice via adrenocortical activation and hippocampal neurogenesis suppression. Mol Psychiatry 2008; 13: 717-728.

10. Sapolsky R, Rivier C, Yamamoto G, Plotsky P, Vale W. Interleukin-1 stimulates the secretion of hypothalamic corticotropin-releasing factor. Science 1987; 238: 522-524.

11. Goshen I, Yirmiya R. Interleukin-1 (IL-1): a central regulator of stress responses. Front Neuroendocrinol 2009; 30: 30-45.

12. Rachal Pugh C, Fleshner M, Watkins LR, Maier SF, Rudy JW. The immune system and memory consolidation: a role for the cytokine IL-1beta. Neurosci Biobehav Rev 2001; 25: 29-41.

13. Association AP. Diagnostic and Statistical Manual of Mental Disorders 4th edn. text revision American Psychiatric Association: Washington, DC, 2000.

14. Ofek K, Krabbe KS, Evron T, Debecco M, Nielsen AR, Brunnsgaad $\mathrm{H}$ et al. Cholinergic status modulations in human volunteers under acute inflammation. $\mathrm{J} \mathrm{Mol} \mathrm{Med} \mathrm{2007;} \mathrm{85:}$ 1239-1251.

15. Pavlov VA, Parrish WR, Rosas-Ballina M, Ochani M, Puerta M, Ochani $\mathrm{K}$ et al. Brain acetylcholinesterase activity controls systemic cytokine levels through the cholinergic anti-inflammatory pathway. Brain Behav Immun 2009; 23: 41-45.

16. Krieg AM. Therapeutic potential of Toll-like receptor 9 activation. Nat Rev Drug Discov 2006; 5: 471-484.

17. Krieg AM, Vollmer J. Toll-like receptors 7,8 , and 9: linking innate immunity to autoimmunity. Immunol Rev 2007; 220: 251-269.

18. Vollmer J. TLR9 in health and disease. Int Rev Immunol 2006; 25: 155-181.

19. Alfonso-Loeches S, Pascual-Lucas M, Blanco AM, Sanchez-Vera I, Guerri C. Pivotal role of TLR4 receptors in alcohol-induced neuroinflammation and brain damage. J Neurosci 2010; 30: 8285-8295.

20. Henry CJ, Huang Y, Wynne A, Hanke M, Himler J, Bailey MT et al. Minocycline attenuates lipopolysaccharide (LPS)-induced neuroinflammation, sickness behavior, and anhedonia. J Neuroinflammation 2008; 5 : 15.

21. Scholtzova H, Kascsak RJ, Bates KA, Boutajangout A, Kerr DJ, Meeker HC et al. Induction of toll-like receptor 9 signaling as a method for ameliorating Alzheimer's disease-related pathology. J Neurosci 2009; 29: 1846-1854.

22. Ehlers M, Ravetch JV. Opposing effects of Toll-like receptor stimulation induce autoimmunity or tolerance. Trends Immunol 2007; 28: 74-79.

23. Vallabhapurapu S, Karin M. Regulation and function of NF-kappaB transcription factors in the immune system. Annu Rev Immunol 2009; 27: 693-733.

24. Latz E, Verma A, Visintin A, Gong M, Sirois CM, Klein DC et al. Ligand-induced conformational changes allosterically activate Toll-like receptor 9. Nat Immunol 2007; 8: 772-779.

25. Puccetti P, Grohmann U. IDO and regulatory T cells: a role for reverse signalling and noncanonical NF-kappaB activation. Nat Rev Immunol 2007; 7: 817-823.

26. Blanchard EB, Jones-Alexander J, Buckley TC, Forneris CA. Psychometric properties of the PTSD Checklist (PCL). Behav Res Ther 1996; 34: 669-673.

27. Shaked I, Meerson A, Wolf Y, Avni R, Greenberg D, Gilboa-Geffen A et al. MicroRNA-132 potentiates cholinergic anti-inflammatory signaling by targeting acetylcholinesterase. Immunity 2009; 31: 965-973.

28. Cohen H, Zohar J, Matar MA, Kaplan Z, Geva AB. Unsupervised fuzzy clustering analysis supports behavioral cutoff criteria in an animal model of posttraumatic stress disorder. Biol Psychiatry 2005; 58: 640-650.

29. Weathers FW, Keane TM, Davidson JR. Clinician-administered PTSD scale: a review of the first ten years of research. Depress Anxiety 2001; 13: 132-156.

30. McCanlies EC, Araia SK, Joseph PN, Mnatsakanova A, Andrew ME, Burchfiel CM et al. C-reactive protein, interleukin-6, and posttraumatic stress disorder symptomology in urban police officers. Cytokine 2011; 55: 74-78.

31. Miller RJ, Sutherland AG, Hutchison JD, Alexander DA. C-reactive protein and interleukin 6 receptor in post-traumatic stress disorder: a pilot study. Cytokine 2001; 13: 253-255.

32. Bonne O, Brandes D, Gilboa A, Gomori JM, Shenton ME, Pitman RK et al. Longitudinal MRI study of hippocampal volume in trauma survivors with PTSD. Am J Psychiatry 2001; 158: 1248-1251.

33. Karl A, Schaefer M, Malta LS, Dorfel D, Rohleder N, Werner A. A meta-analysis of structural brain abnormalities in PTSD. Neurosci Biobehav Rev 2006; 30: 1004-1031.

34. Adamec R, Head D, Soreq $H$, Blundell J. The role of the read through variant of acetylcholinesterase in anxiogenic effects of predator stress in mice. Behav Brain Res 2008; 189: 180-190.

35. Nijholt I, Farchi N, Kye M, Sklan EH, Shoham S, Verbeure B et al. Stress-induced alternative splicing of acetylcholinesterase results in enhanced fear memory and long-term potentiation. Mol Psychiatry 2004; 9: 174-183.

36. Evron T, Moyal-Segal LB, Lamm N, Geffen A, Soreq H. RNA-targeted suppression of stress-induced allostasis in primate spinal cord neurons. Neurodegener Dis 2005; 2 : $16-27$. 
37. Watkins LR, Maier SF, Goehler LE. Cytokine-to-brain communication: a review \& analysis of alternative mechanisms. Life Sci 1995; 57: 1011-1026.

38. Schmidt ED, Aguilera G, Binnekade R, Tilders FJ. Single administration of interleukin-1 increased corticotropin releasing hormone and corticotropin releasing hormone-receptor mRNA in the hypothalamic paraventricular nucleus which paralleled long-lasting (weeks) sensitization to emotional stressors. Neuroscience 2003; 116: 275-283.

39. Koo JW, Duman RS. IL-1 beta is an essential mediator of the antineurogenic and anhedonic effects of stress. Proc Natil Acad Sci USA 2008; 105: 751-756.

40. Potter E, Behan DP, Fischer WH, Linton EA, Lowry PJ, Vale WW. Cloning and characterization of the CDNAs for human and rat corticotropin releasing factor-binding proteins. Nature 1991; 349: 423-426.

41. Weeber EJ, Atkins CM, Selcher JC, Varga AW, Mirnikjoo B, Paylor R et al. A role for the beta isoform of protein kinase $C$ in fear conditioning. J Neurosci 2000; 20: 5906-5914.

42. Mayford M, Bach ME, Huang YY, Wang L, Hawkins RD, Kandel ER. Control of memory formation through regulated expression of a CaMKII transgene. Science 1996; 274: 1678-1683.

43. Gashler A, Sukhatme VP. Early growth response protein 1 (Egr-1): prototype of a zincfinger family of transcription factors. Prog Nucleic Acid Res Mol Biol 1995; 50: 191-224.

44. Hemmi H, Takeuchi O, Kawai T, Kaisho T, Sato S, Sanjo H et al. A Toll-like receptor recognizes bacterial DNA. Nature 2000; 408: 740-745.

45. Otto C, Kovalchuk Y, Wolfer DP, Gass P, Martin M, Zuschratter W et al. Impairment of mossy fiber long-term potentiation and associative learning in pituitary adenylate cyclase activating polypeptide type I receptor-deficient mice. J Neurosci 2001; 21: 5520-5527.
46. Cohen $\mathrm{H}$, Zohar J. An animal model of posttraumatic stress disorder: the use of cut-off behavioral criteria. Ann N Y Acad Sci 2004; 1032: 167-178.

47. Argov Z, McKee D, Agus S, Brawer S, Shlomowitz N, Yoseph OB et al. Treatment of human myasthenia gravis with oral antisense suppression of acetylcholinesterase. Neurology 2007; 69: 699-700.

48. Tracey KJ. Reflex control of immunity. Nat Rev Immunol 2009; 9: 418-428.

49. Berlant J. New drug development for post-traumatic stress disorder. Curr Opin Investig Drugs 2003; 4: 37-41.

50. Ho SP, Hartig PR. Antisense oligonucleotides for target validation in the CNS. Curr Opin Mol Ther 1999; 1: 336-343.

51. Kirby ED, Friedman AR, Covarrubias D, Ying C, Sun WG, Goosens KA et al. Basolateral amygdala regulation of adult hippocampal neurogenesis and fear-related activation of newborn neurons. Mol psychiatry (in press).

(c) Translational Psychiatry is an open-access journal published by Nature Publishing Group. This work is licensed under the Creative Commons Attribution-Noncommercial-No Derivative Works 3.0 Unported License. To view a copy of this license, visit http://creativecommons.org/licenses/by-nc-nd/3.0/

Supplementary Information accompanies the paper on the Translational Psychiatry website (http://www.nature.com/tp) 